\title{
Synthesis of new substituted thieno[2,3-d]imidazolones from hydantoin
}

\author{
Lalla Aïcha Ba, ${ }^{a}$ Gilbert Kirsch, ${ }^{a *}$ and Jérémie Castello ${ }^{\mathrm{b}}$ \\ ${ }^{a}$ Laboratoire d'Ingénierie Moléculaire et Biochimie Pharmacologique, Institut Jean Barriol, \\ Université Paul Verlaine, 1 Bd Arago, 57078 METZ Technopole,France. ${ }^{b}$ Laboratoire de \\ Spectrométrie de Masse et Chimie Laser, Institut Jean Barriol, Université Paul Verlaine, 1 Bd \\ Arago, 57078 METZ Technopole,France \\ E-mail: kirsch@sciences.univ-metz.fr
}

This manuscript is dedicated to Pr. Alain Krief

\begin{abstract}
1,3-Dibenzyl-5-chloro-2-oxo-4-imidazoldinecarbaldehyde 3 was prepared in two steps from hydantoin using Vilsmeier-Haack reagent. Treatment of $\mathbf{3}$ with sodium sulfide nonahydrate and different activated halides or methyl thioglycolate afforded new substituted thieno[2,3d]imidazolones.
\end{abstract}

Keywords: Hydantoin, Vilsmeier-Haack reagent, $\alpha, \beta$ substituted $\beta$-chloroacrolein, sodium sulfide nonahydrate, methyl thioglycolate, thieno[2,3- $d]$ imidazolone

\section{Introduction}

Thieno[2,3-d]imidazolone $\mathbf{I}$ is an interesting fused heterocyclic ring which can replace the benzimidazole moiety in pharmaceutical drugs ${ }^{1,2,3}$. This compound was previously prepared from various aminothiophene carboxylic acid derivatives such as the azide $\mathbf{I I}^{4,5}$ or the anhydride III $^{1}$

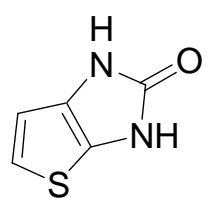

I

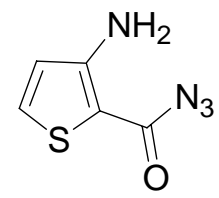

II

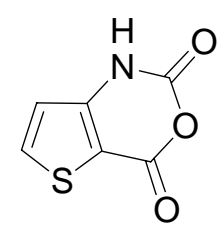

III

These methods required several steps and needed the synthesis of the two rings. Moreover, the thiophene ring obtained by this way was not functionalized. We were interested in finding a 
novel pathway to synthesize thieno[2,3-d]imidazolones 4 bearing a functional group on the thiophene ring for further transformation. A method developed earlier in our laboratory ${ }^{6}$ allows the preparation of functionalized thiophenes starting from the $\beta$-chloroacrolein moiety. Application of this method to a N-protected hydantoin was used to get access to thieno[2,3d]imidazolones $\mathbf{4}$ starting from the commercially available hydantoin $\mathbf{1}$ as outlined in Scheme 1.<smiles>O=C(O)[C@@H](NC(=O)N1C(=O)CNC1=O)C(F)(F)Br</smiles>

1<smiles>O=C1CN(Cc2ccccc2)C(=O)N1Br</smiles>

2<smiles>O=Cc1[nH]c(=O)n(Cc2ccccc2)c1Cl</smiles>

3<smiles></smiles>

4

Scheme 1

\section{Results and Discussion}

Hydantoin had to be protected before reacting with the Vilsmeier-Haack reagent. This was done by benzylation using either benzyl bromide or benzyl chloride in $\mathrm{DMF}^{7}$ (scheme 2). 1,3Dibenzyl-2,4-imidazolidinedione 2 was isolated in $90 \%$ yield.<smiles>O=C1CNC(=O)N1</smiles>

1

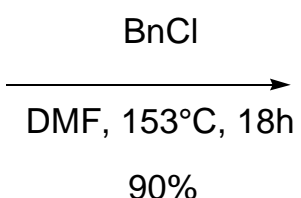

$90 \%$

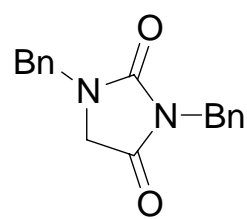

2

Scheme 2

The N-protected hydantoin 2 was reacted with $\mathrm{DMF}-\mathrm{POCl}_{3}$ under various conditions, see Table 1.

Table 1

\begin{tabular}{cccc}
\hline Entry & $\begin{array}{c}\text { Molar ratio } \\
\mathrm{POCl}_{3} / \mathrm{DMF} / \mathbf{2}\end{array}$ & Solvent/time $(\mathrm{h}) / \mathrm{T}\left({ }^{\circ} \mathrm{C}\right)$ & Product, yield \\
\hline $\mathbf{1}$ & $3: 3: 1$ & $\mathrm{DCM} / 3 /$ reflux & no reaction \\
$\mathbf{2}$ & $3: 3: 1$ & $\mathrm{DMF} / 3 / 60$ & mixture of $\mathbf{2}, \mathbf{3}, \mathbf{5}$ \\
$\mathbf{3}$ & $2: 1: 1$ & $\mathrm{DMF} / 16 / 80$ & mixture of $\mathbf{2}, \mathbf{3}, \mathbf{5}$ \\
$\mathbf{4}$ & $3: 3: 1$ & $\mathrm{DMF} / 3 / 153$ & mixture of $\mathbf{2}, \mathbf{3}, \mathbf{5}$ \\
$\mathbf{5}$ & $10: 10: 1$ & Neat $/ 5 / 90$ & $\mathbf{3}, 80 \%$ \\
\hline
\end{tabular}


No reaction was observed in dichloromethane (DCM) (entry 1). Changing from DCM to DMF (entry 2) gives a mixture of starting material 2, compound 3 and the chloro derivative ${ }^{8} \mathbf{5}$ in a ratio of 3:4:1 approximately determined by NMR (Scheme 3). The mixture could not be separated by column chromatography. The same phenomenon was observed in similar experiments (entry $3^{9}$ and 4 ).<smiles>O=C1C[Sn](Br)CC1=O</smiles>

2

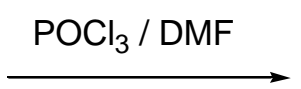<smiles>O=Cc1c(Cl)n(Br)c(=O)n1Cc1ccccc1</smiles>

3<smiles>O=C1N[C@H](Br)C=C1Cl</smiles>

5

\section{Scheme 3}

It was only when compound 2 was heated for five hours at $90^{\circ} \mathrm{C}$ with a 10 fold excess of the Vilsmeier-Haack reagent that $\mathbf{3}$ was formed in high yield (entry 5). In this case $\mathbf{3}$ could be purified by column chromatography and afforded a light yellow solid in $80 \%$ yield. In fact, longer heating (12 hours) under the same conditions gave directly after treatment the crystalline compound 3 without further purification. Tan and $\mathrm{Chen}^{10}$ have recently described compound $\mathbf{3}$ as an oil.

From derivative 3, using a method developed earlier in our laboratory, ${ }^{6}$ we prepared some new thieno[2,3-d] imidazolones. Condensation of 3 with sodium sulfide nonahydrate in DMF or ethanol followed by the addition of an activated halide and cyclisation with a base, afforded derivatives 4a-d (Scheme 4, Table 2)<smiles>O=CC1=C(Cl)[B]C(=O)N1Br</smiles>

3
1) $\mathrm{Na}_{2} \mathrm{~S} .9 \mathrm{H}_{2} \mathrm{O}$, DMF or EtOH

2) $\mathrm{XCH}_{2} Y$

3) base

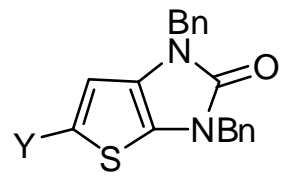

4a-d

\section{Scheme 4}


Table 2. Thieno[2,3-d]imidazolones 4a-d prepared from the aldehyde 3 (yields not optimized)

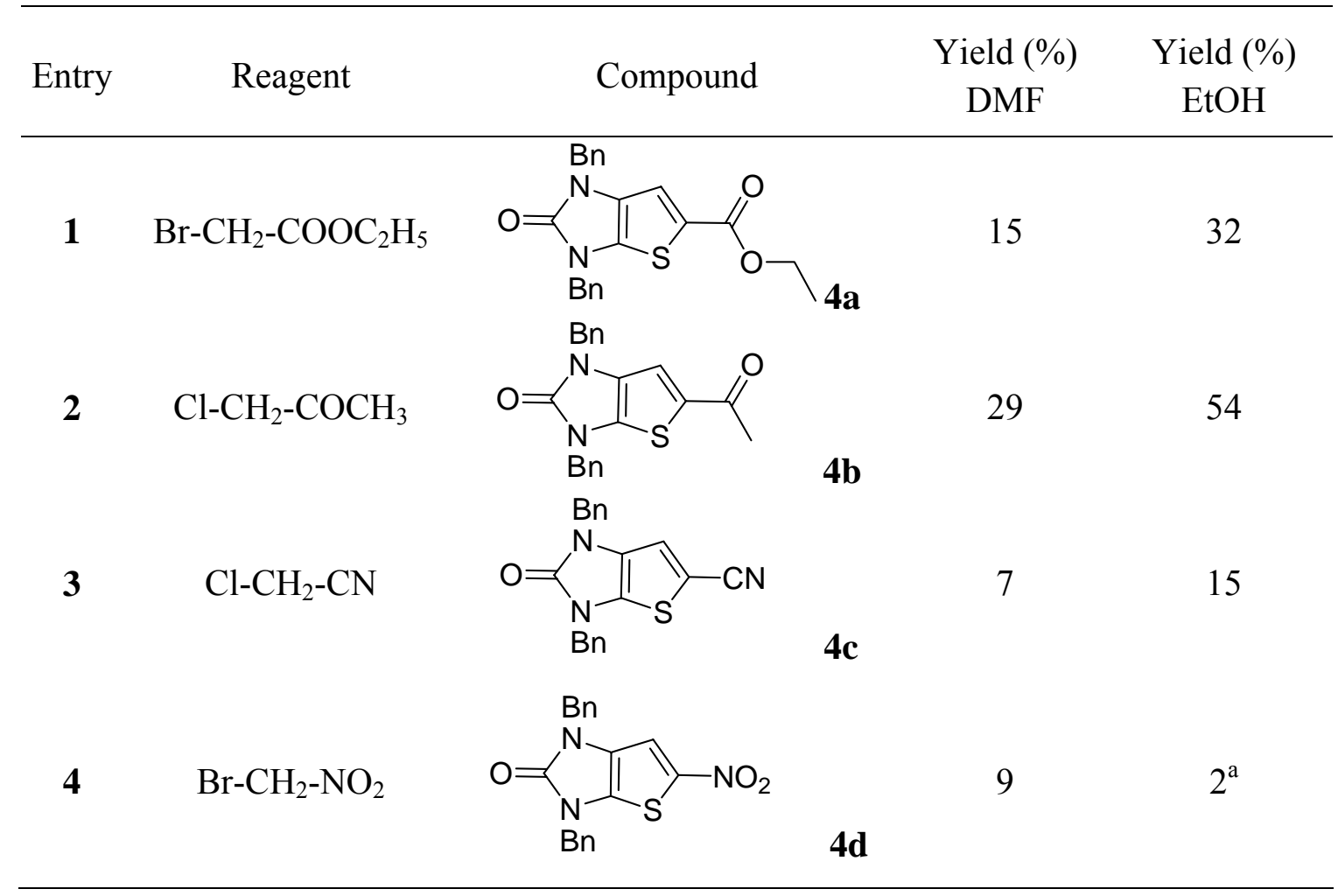

${ }^{\mathrm{a}}$ the reaction was performed in dimethoxyethane (DME).

The thieno[2,3-d]imidazolone 4e bearing a methyl ester group was prepared by direct condensation of methyl thioglycolate (Scheme 5) and delivered 5e in a yield very similar to that one using sodium sulfide and ethyl bromoacetate.<smiles></smiles>

3

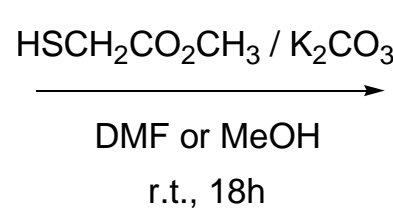

r.t., $18 \mathrm{~h}$<smiles></smiles>

$4 e$

DMF: $14 \%$

$\mathrm{MeOH}: 36 \%$

\section{Scheme 5}

We can notice that after the addition of the activated halide TLC showed many by-products which could not be isolated separately. For example the poor yield obtained for $\mathbf{4 d}$ can be explained by formation of the disulfide as it has already been shown by Stirling and co- 
workers ${ }^{11}$. These facts explain that the final pure compounds were recovered in low yields after column chromatography on silica gel.

In conclusion, we have developed a novel route to substituted thieno[2,3- $d$ ]imidazolones 4 in three steps from commercial hydantoin 1. The key intermediate was the $\alpha, \beta$ substitued $\beta$ chloroacrolein 3. Further investigations in the synthesis of disubstituted thieno[2,3d] imidazolones from $\alpha, \beta$ substitued $\beta$-chloroacrylonitrile derived from 3 and in the synthesis of other fused heterocyclic ring systems are in progress.

\section{Acknowledgements}

The authors want to thank Véronique Poddig for recording NMR spectra; Dr Dan Bernardi for his help in bibliographic research and Dr Juan-Carlos Rodriguez-Dominguez for helpful discussion.

\section{Experimental Section}

General Procedures. EtOH, MeOH and DME were distilled from sodium, DMF 99\% was purchased from Aldrich. Column chromatography was performed using silica gel 60A (0.070$0.200 \mathrm{~mm}$ ). Melting points were measured in a SMP3 Stuart Scientific apparatus and were uncorrected. ${ }^{1} \mathrm{H}(250 \mathrm{MHz})$ and ${ }^{13} \mathrm{C}$ NMR $(62.89 \mathrm{MHz})$ spectra were recorded in DMSO- $d_{6}$ in a Bruker AC 250 spectrometer. All high resolution mass spectra are acquired in positive detection mode using an IonSpec (now Varian) Fourier Transform Mass Spectrometer, equipped with 9.4 Tesla Actively Shielded magnet, and an electrospray ionization source (ESI). Samples were prepared in a solution of water/methanol $(\mathrm{v} / \mathrm{v})$ to obtain a concentration around $10^{-6} \mathrm{~mol} . \mathrm{L}^{-1}$. They were infused into the ESI source potentials at a flow rate of $2 \mu \mathrm{L} \mathrm{min}{ }^{-1}$. The source temperature was $120^{\circ} \mathrm{C}$ and a countercurrent flow of nitrogen gas was used to assist in desolvation of the droplets produced by ESI from a grounded needle directed to a metal-capped nickel-coated glass capillary $(3.8 \mathrm{kV})$. Mass spectra were acquired after an accumulation time of 20 seconds in a hexapole accumulation chamber. The mass range for ESI experiments was from $\mathrm{m} / \mathrm{z}=100$ to 1000 .

1,3-Dibenzyl-2,4-imidazolidinedione (2). Benzyl chloride (37.95 $\mathrm{mL}, 0.33 \mathrm{~mol})$ was added to a solution of hydantoin $(15 \mathrm{~g}, 0.15 \mathrm{~mol})$ and $\mathrm{K}_{2} \mathrm{CO}_{3}(45.57 \mathrm{~g}, 0.33 \mathrm{~mol})$ in $100 \mathrm{~mL}$ of dimethyl formamide (DMF). The mixture was stirred at $153^{\circ} \mathrm{C}$ for 16 hours and quenched with water $(1$ L). The precipitate was filtered off. Purification of the crude product by crystallisation in EtOH provided pure 2 as a yellow solid $90 \%, \mathrm{mp} 66-68^{\circ} \mathrm{C}(\mathrm{EtOH})\left(\mathrm{mp}_{\mathrm{lit}}{ }^{7} 46-48^{\circ} \mathrm{C}\right),{ }^{1} \mathrm{H}$ NMR $\delta(\mathrm{ppm})$ 7.38-7.36 (m, 10H), $4.64\left(\mathrm{~s}, 2 \mathrm{H}\right.$ ), $4.57(\mathrm{~s}, 2 \mathrm{H}), 4.03(\mathrm{~s}, 2 \mathrm{H}) ;{ }^{13} \mathrm{C}$ NMR $\delta$ (ppm) 169.9, 156.3, $136.5,136.3,128.6-127.3(10 \mathrm{C}), 49.5,45.8,41.5$. 
1,3-Dibenzyl-5-chloro-2-oxo-4-imidazoldinecarbaldehyde (3). $\mathrm{POCl}_{3}(32.9 \mathrm{~mL}, 0.35 \mathrm{~mol})$ was added dropwise to DMF at $0^{\circ} \mathrm{C}(27.3 \mathrm{~mL}, 0.35 \mathrm{~mol})$, the mixture was stirred at $0^{\circ} \mathrm{C}$ for $30 \mathrm{~min}$ before 2 ( $10 \mathrm{~g}, 0.035 \mathrm{~mol})$ was added. The mixture was stirred at $90^{\circ} \mathrm{C}$ for 5 hours. The reaction mixture was cooled to room temperature and quenched with water $(300 \mathrm{~mL})$. The solution was brought to $\mathrm{pH} 4$ by addition of $\mathrm{NaOAc}$ and extracted with $\mathrm{Et}_{2} \mathrm{O}$. The combined ether layers were washed with brine $(100 \mathrm{~mL})$, dried over $\mathrm{MgSO}_{4}$, filtered and concentrated in vacuo. The crude product was purified by silica gel column chromatography (cyclohexane-ethyl acetate 9:1) to afford 3 as a pale yellow solid $80 \%, \mathrm{mp}: 80^{\circ} \mathrm{C}$. When the reaction mixture was heated for 12 hours, the standard work-up procedure afforded 3 in a pure state without further purification. ${ }^{1} \mathrm{H}$ NMR $\delta(\mathrm{ppm}) 9.43(\mathrm{~s}, 1 \mathrm{H}), 7.21-7.36(\mathrm{~m}, 10 \mathrm{H}), 5.14(\mathrm{~s}, 1 \mathrm{H}), 4.98(\mathrm{~s}, 1 \mathrm{H}) ;{ }^{13} \mathrm{C}$ NMR $\delta(\mathrm{ppm})$ $175.8,150.8,137.3,135.6,128.7-127.0$ (10 C), 117.5, 44.9, 44.7; HRMS (ESI): $(\mathrm{M}+\mathrm{H})^{+}$ calculated 327.0895 , found 327.0897

\section{Thieno[2,3-d]imidazolones. General procedure for 4a-d}

$\mathrm{Na}_{2} \mathrm{~S} .9 \mathrm{H}_{2} \mathrm{O}$ (1.1 eq.) in $3 \mathrm{~mL}$ of DMF or EtOH (DME when bromonitromethane was used) was heated at $40^{\circ} \mathrm{C}$ for 1 hour. Then 3 was added. After stirring for 2 hours at $60^{\circ} \mathrm{C}$ the halide $(1.1$ eq.) was added and the mixture was stirred for 2-3 hours. After cooling at $0^{\circ} \mathrm{C}$, a solution of sodium ethoxide (1.1 eq. of sodium in $1 \mathrm{~mL}$ of absolute ethanol) was added dropwise. The mixture was stirred for 1-2 hours at room temperature. The reaction was quenched with water $(20 \mathrm{~mL})$ and extracted with ethyl acetate $(3 \times 10 \mathrm{~mL})$. The combined organic layers were dried with $\mathrm{MgSO}_{4}$, filtered, and concentrated to give crude products 4a-d which were purified by column chromatography (DCM).

Ethyl 1,3-dibenzyl-2-oxo-2,3-dihydro-1H-thieno[2,3-d]imidazole-5-carboxylate

(4a). Colorless solid, mp $110-115^{\circ} \mathrm{C} ;{ }^{1} \mathrm{H}$ NMR $\delta$ (ppm) 7.53 (s, 1H), 7.37-7.33 (m, 10H), 5.04 (s, 2H), 4.99 (s, 2H), 4.21-4.12 (q, $J=7 \mathrm{~Hz}, 2 \mathrm{H}), 1.22-1.16$ (t, $J=7 \mathrm{~Hz}, 3 \mathrm{H}) ;{ }^{13} \mathrm{C} \mathrm{NMR} \delta(\mathrm{ppm}) 161.9$, 154.8, 136.7, 136.3, 134.7, 129.7, 128.8 -126.9 (10C), 121.5, 116.6, 60.5, 46.5, 45.6, 14.1; HRMS (ESI): $(\mathrm{M}+\mathrm{H})^{+}$calculated 393.12674, found 393.12673

5-Acetyl-1,3-dibenzyl-1,3-dihydro-2H-thieno[2,3-d]imidazol-2-one (4b). Brown solid, mp $100^{\circ} \mathrm{C} ;{ }^{1} \mathrm{H}$ NMR $\delta(\mathrm{ppm}) 7.77(\mathrm{~s}, 1 \mathrm{H}), 7.36-7.34(\mathrm{~m}, 10 \mathrm{H}), 5.02(\mathrm{~s}, 2 \mathrm{H}), 5.00(\mathrm{~s}, 2 \mathrm{H}) ;{ }^{13} \mathrm{C}$ NMR $\delta$ (ppm) 189.5, 154.8, 136.7, 134.6, 134.1, 131.9, 128.8-127.5 (10 C), 117.0, 46.5, 45.7, 25.5; HRMS (ESI): $(\mathrm{M}+\mathrm{H})^{+}$calculated 363.11617, found 363.11618

1,3-Dibenzyl-2-oxo-2,3-dihydro-1H-thieno[2,3-d]imidazole-5-carbonitrile (4c). Brown solid, mp $54{ }^{\circ} \mathrm{C} ;{ }^{1} \mathrm{H}$ NMR $\delta(\mathrm{ppm}) 7.69(\mathrm{~s}, 1 \mathrm{H}), 7.34-7.22(\mathrm{~m}, 10 \mathrm{H}), 5.02(\mathrm{~s}, 2 \mathrm{H}), 4.99(\mathrm{~s}, 2 \mathrm{H}) ;{ }^{13} \mathrm{C}$ NMR $\delta$ (ppm) 154.3, 140.6, 136.1, 133.5, 133.5, 129.2-127.0 (10C), 126.3, 114.0, 47.0, 45.7; HRMS (ESI): $(\mathrm{M}+\mathrm{H})^{+}$calculated 346.10086, found 346.10066

1,3-Dibenzyl-5-nitro-1,3-dihydro-2H-thieno[2,3-d]imidazol-2-one (4d). Deep yellow solid, mp 62-64 ${ }^{\circ} \mathrm{C} ;{ }^{1} \mathrm{H}$ NMR $\delta(\mathrm{ppm}) 8.03(\mathrm{~s}, 1 \mathrm{H}), 7.44-7.27(\mathrm{~m}, 10 \mathrm{H}), 5.05(\mathrm{~s}, 2 \mathrm{H}), 5.03(\mathrm{~s}, 2 \mathrm{H}) ;{ }^{13} \mathrm{C}$ NMR $\delta$ (ppm) 153.6, 137.7, 137.7, 136.1, 128.9, 128.7-126.8 (10C), 120.6, 116.0, 99.0, 44.9, 44.5; HRMS (ESI): $(\mathrm{M}+\mathrm{H})^{+}$calculated 379.11109, found 379.11107 
Methyl 1,3-dibenzyl-2-oxo-2,3-dihydro-1H-thieno[2,3-d]imidazole-5-carboxylate (4e). To a solution of $3(0.5 \mathrm{~g}, 1.53 \mathrm{mmol})$ in $3 \mathrm{~mL}$ of DMF or methanol was added methyl thioglycolate $(0.136 \mathrm{~mL}, 1.53 \mathrm{mmol})$ and $\mathrm{K}_{2} \mathrm{CO}_{3}(0.211 \mathrm{~g}, 1.53 \mathrm{mmol})$. The mixture was stirred at room temperature for 18 hours. Sodium methoxide $(0.053 \mathrm{~g}(2.3 \mathrm{mmol})$ of sodium in $1 \mathrm{~mL}$ of methanol) was added at $0^{\circ} \mathrm{C}$. After two hours the mixture was evaporated and the residue was poured into $100 \mathrm{~mL}$ of water and extracted with ethyl acetate $(3 \times 20 \mathrm{~mL})$. The organic layers were dried over $\mathrm{MgSO}_{4}$, filtered and evaporated. The crude product was purified by column chromatography (DCM) to afford 4e as a yellow solid, yield 14\% in DMF $36 \%$ in $\mathrm{MeOH}, \mathrm{mp}$ 141-143 ${ }^{\circ} \mathrm{C} ;{ }^{1} \mathrm{H}$ NMR $\delta(\mathrm{ppm}) 7.54(\mathrm{~s}, 1 \mathrm{H}), 7.37-7.34(\mathrm{~m}, 10 \mathrm{H}), 5.03(\mathrm{~s}, 2 \mathrm{H}), 4.99$ (s, 2H), 3.69 $(\mathrm{s}, 3 \mathrm{H}) ;{ }^{13} \mathrm{C}$ NMR $\delta$ (ppm) 162.3, 154.8, 136.7, 134.6 (2C), 129.8, 128.8-127.2 (10 C), 121.1, 116.7, 51.8, 46.6, 45.6; HRMS (ESI): $(\mathrm{M}+\mathrm{H})^{+}$calculated 366.09069, found 366.09076.

\section{References and Notes}

1. Fabis, F.; Jolivet-Fouchet, S.; Rault, S. Tetrahedron 1999, 55, 6167.

2. Dabaeva, V. V.; Noravyan, A. S.; Madakyan, V. N.; Enokyan, B. D. Chem. Heterocycl. Compd. 1997, 33, 741.

3. Preston, P. N.; Sood, S. K. J. Chem. Soc., Perkin Trans I 1976, 80.

4. Binder, D.; Hillbrand, F.; Noe, C. R. J. Chem. Res. (M) 1979, 1151.

5. Huddleston, P. R.; Barker, J. M.; Adamczewska, Y. Z.; Wood, M. L.; Holmes, D. J. Chem. Res. (M) 1993, 548.

6. Cagniant, P.; Kirsch, G. C.R. Acad Sc. Paris 1975, $t$ 281, 35.

7. Ulgheri, F. Tetrahedron. Lett. 2004, 45, 1047.

8. Formation of the chloro intermediate $\mathbf{5}$ has been proven in other cases: Lilienkampf, A.; Johansson, M. P.; Wähälä. K. Org. Lett. 2003, 5, 3387.

9. Baranov, S. N.; Kochkanyan, R. O.; Zaritovskii, A. N.; Belova, G. I.; Radkova, S. S. Chem. Heterocycl. Compd. 1975, 11, 73.

10. Tan, X.; Chen, C. Angew. Chem. Int. Ed. 2006, 45, 4345.

11. Fishwick, B. R.; Rowles, D. K.; Stirling, C. J. M. J. Chem. Soc., Perkin Trans I 1986, 1171. 